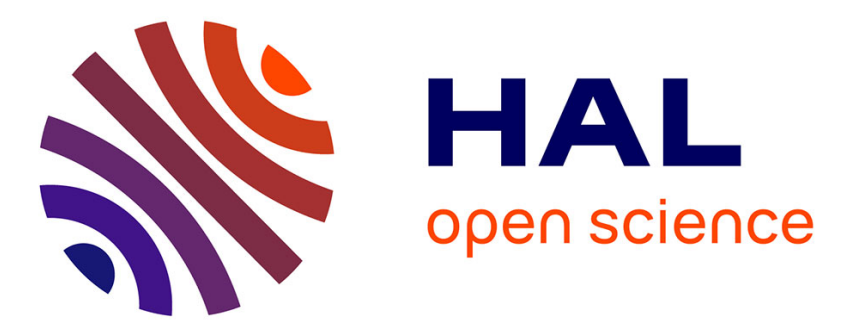

\title{
T-cadherin gene variants are associated with type 2 diabetes and the Fatty Liver Index in the French population
}

A. Nicolas, R. Aubert, N. Bellili-Muñoz, B. Balkau, F. Bonnet, J. Tichet, G. Velho, M. Marre, R. Roussel, Frederic Fumeron

\section{To cite this version:}

A. Nicolas, R. Aubert, N. Bellili-Muñoz, B. Balkau, F. Bonnet, et al.. T-cadherin gene variants are associated with type 2 diabetes and the Fatty Liver Index in the French population. Diabetes \& Metabolism, 2016, 10.1016/j.diabet.2016.05.005 . hal-01346617

\section{HAL Id: hal-01346617 https://hal.sorbonne-universite.fr/hal-01346617}

Submitted on 19 Jul 2016

HAL is a multi-disciplinary open access archive for the deposit and dissemination of scientific research documents, whether they are published or not. The documents may come from teaching and research institutions in France or abroad, or from public or private research centers.
L'archive ouverte pluridisciplinaire HAL, est destinée au dépôt et à la diffusion de documents scientifiques de niveau recherche, publiés ou non, émanant des établissements d'enseignement et de recherche français ou étrangers, des laboratoires publics ou privés. 
T-cadherin gene variants are associated with type 2 diabetes in the French Population

Anthony Nicolas ${ }^{\mathrm{a}, \mathrm{b}, \mathrm{c}}$, Roberte Aubert ${ }^{\mathrm{a}}$, Naima Bellili-Muñoz ${ }^{\mathrm{a}}$, Beverley Balkau ${ }^{\mathrm{d}}$, Fabrice

Bonnet $^{\mathrm{d}, \mathrm{e}}$, Jean Tichet ${ }^{\mathrm{f}}$, Gilberto Velho ${ }^{\mathrm{a}}$, Michel Marre ${ }^{\mathrm{a}, \mathrm{g}, \mathrm{h}}$, Ronan Roussel ${ }^{\mathrm{a}, \mathrm{b}, \mathrm{c}, \mathrm{g}, \mathrm{h}}$, Frédéric Fumeron $^{\mathrm{a}, \mathrm{b}, \mathrm{c}, \mathrm{h}}$

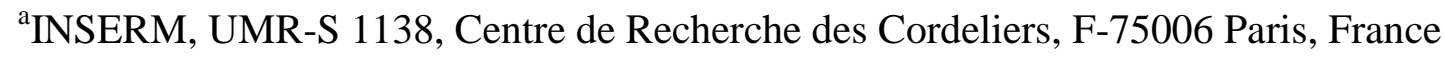

${ }^{\mathrm{b}}$ Sorbonne Universités, UPMC Univ Paris 06, UMR-S 1138, Centre de Recherche des

Cordeliers, F-75006 Paris, France

${ }^{c}$ Université Paris Descartes, Sorbonne Paris Cité, UMR_S 1138, Centre de Recherche des

Cordeliers, F-75006 Paris, France.

${ }^{\mathrm{d}}$ INSERM, Centre for research in Epidemiology and Population Health (CESP), U1018,

Villejuif, France, University Paris-Sud, University Versailles Saint-Quentin, UMRS 1018,

France

${ }^{\mathrm{e}}$ Department of Endocrinology and Diabetology, Centre Hospitalier Universitaire de Rennes, University Rennes 1, Rennes, France

${ }^{\mathrm{f}}$ IRSA, LA Riche, France

${ }^{\mathrm{g}}$ Department of Diabetology, Endocrinology and Nutrition, APHP - Bichat Hospital, Paris,

France

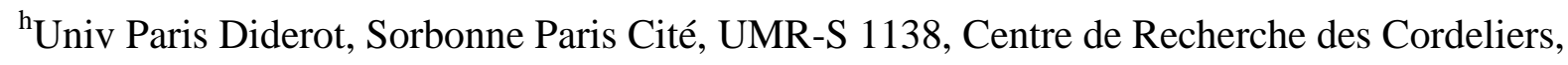
F-75006 Paris, France

Corresponding author : Frédéric Fumeron, INSERM, Centre de Recherche des Cordeliers, Research Unit 1138, 15 rue de l'Ecole de Médecine, Paris 75006, France,

telephone number: 331442781 14; fax number: 33144276421

e-mail address: frederic.fumeron@inserm.fr

word count: 2612

abstract word count: 250

number of tables: 5 


\section{Abbreviations}

BMI, body mass index; CI, confidence Interval; FLI, fatty liver index; GGT, gammaglutamyl-transferase; GWAS, genome-wide association study; HMW, high molecular weight; LMW, low molecular weight; MAF, minor allele frequency; MMW, medium molecular weight; NAFLD, non-alcoholic fatty liver disease; OR, odds-ratio; TCAD, T-cadherin 


\section{Abstract}

Aim

Adiponectin is an adipocyte-secreted protein associated with insulin sensitivity. T-cadherin is a receptor for high and medium molecular weight adiponectin. In GWAS, T-cadherin gene ( $C D H 13)$ polymorphisms are associated with circulating adiponectin levels. We investigate the associations between genetic variants of $\mathrm{CDH} 13$ and type 2 diabetes, and related parameters, in a Caucasian population.

\section{Methods}

Two polymorphisms of $C D H 13$ (rs11646213 and rs3865188) were genotyped in French cohorts, firstly in a general population D.E.S.I.R. $(\mathrm{N}=5212)$, and secondly in people with type 2 diabetes, DIABHYCAR ( $\mathrm{N}=3123)$. Adiponectin levels at baseline were measured in D.E.SI.R. participants who were normoglycaemic at baseline but hyperglycaemic after 3 years $(n=230)$ and controls who remained normoglycaemic $(n=226)$.

\section{Results}

In a cross sectional analysis, $C D H 13$ genotype distributions differed between people with and without type 2 diabetes with odds-ratio (95\% CI) for type 2 diabetes of 1.11 (1.04-1.18) $(\mathrm{p}=0.001)$, and $0.92(0.87-0.98)(\mathrm{p}=0.01)$ for $\mathrm{rs} 11646213$ and $\mathrm{rs} 3865188$, respectively. The rs 11646213 variant, associated with a higher odds-ratio for type 2 diabetes, was also associated with higher BMI ( $\mathrm{p}=0.03), \mathrm{HbA1c}(\mathrm{p}=0.006)$ and lower plasma adiponectin levels $(\mathrm{p}=0.03)$ in the D.E.S.I.R. general population. Conversely, the variant rs3865188, associated with a lower odds-ratio for type 2 diabetes, was also associated with lower BMI ( $\mathrm{p}=0.03)$, HbA1c $(\mathrm{p}=0.02)$ and fatty liver index $(\mathrm{p} \leq 0.01)$ and higher plasma adiponectin $(\mathrm{p}=0.002)$. The associations with $\mathrm{HbA1c}$, fatty liver index and adiponectin levels persisted after adjustments on BMI. 


\section{Conclusion}

CDH13 polymorphisms were associated with prevalent type 2 diabetes in this French population. The association may be mediated through effects on BMI and/or plasma adiponectin.

\section{Keywords}

T-cadherin; genetic polymorphisms; adiponectin; type 2 diabetes; body mass index; fatty liver index 


\section{Introduction}

Adiponectin is an adipokine mainly secreted by adipocytes. Adiponectin levels have been associated with type 2 diabetes and various related traits, including non-alcoholic fatty liver disease (NAFLD) [1-4].

It circulates in the blood in a number of complexes which include trimers described as lowmolecular weight (LMW) oligomers, hexamers as medium-molecular weight (MMW), and high-molecular weight (HMW) multimers (12-, 18-mers and possibly larger). The HMW isomer is the most abundant and has been described as responsible for the beneficial effects of adiponectin. Adiponectin acts through two main receptors AdipoR1, AdipoR2 and an additional receptor, T-cadherin, which binds only to MMW and HMW adiponectin [5].

T-cadherin, unlike other cadherins, is not responsible for cell adhesion but participates in intracellular signal transmission [6]. It has been demonstrated that T-cadherin is essential for the cardioprotective effect of adiponectin [7], and has been associated with insulin secretion [8].

In Genome Wide Association Studies (GWAS), T-cadherin gene (CDH13) polymorphisms were associated with circulating adiponectin levels $[9,10]$. $C D H 13$ polymorphisms were also associated with the risk of the metabolic syndrome and blood pressure in Europeans $[11,12]$ and type 2 diabetes in Asian men [13]. In addition, a meta-analysis showed that a genetic score, including $C D H 13$, associated with adiponectin levels, might influence the risk of type 2 diabetes in a multiethnic population [9].

In our previous studies on the D.E.S.I.R. cohort, we have found that low adiponectin levels were associated with a higher risk of hyperglycemia and type 2 diabetes. A low fatty liver index (FLI), surrogate marker of liver steatosis, was associated with a lower risk of the incidence of type 2 diabetes at the 9-year follow-up [14]. The aim of the present study was to 
test the associations of $\mathrm{CDH} 13$ polymorphisms with adiponectin levels and type 2 diabetes risk, as well as related metabolic traits including the FLI, in the French D.E.S.I.R. study population. We also performed a case-control comparison between people without type 2 diabetes in D.E.S.I.R. and the people with type 2 diabetes from the D.E.S.I.R. and DIABHYCAR cohort.

\section{Material and Methods}

\section{Participants}

Two populations were included: volunteers from the general French population in D.E.S.I.R. and patients with type 2 diabetes in DIABHYCAR.

The D.E.S.I.R. study is a prospective study that included 2,576 men and 2,636 women, aged 30-65 years, recruited from volunteers who were offered periodic health examinations free of charge by the French Social Security system in 10 health examination centers from the western part of France. They were clinically and biologically evaluated at visits every 3 years, and the final examination was 9 years after inclusion. The study was approved by the ethics committee of the Kremlin Bicêtre Hospital, and all participants signed an informed consent. The clinical and biological measurements have been extensively previously described [15]. The DIABHYCAR was a 6-year clinical trial in men and women with type 2 diabetes and included 3,137 unrelated French people. The trial tested whether a low dose of Ramipril, an ACE inhibitor, would reduce cardiovascular and/or renal events. Negative results from this study were published previously [16,17]. Participants gave written informed consent and study protocols were approved by the Ethics Committee of Angers University Hospital. Characteristics of the D.E.S.I.R. and DIABHYCAR cohorts are presented in Table 1.

\section{Adiponectin Assay Measurement}


In D.E.S.I.R., adiponectin levels were measured by radioimmunoassay (RIA) at baseline, in 456 people with baseline normoglycaemia (fasting plasma glucose $<6.1 \mathrm{mmol} / \mathrm{l}$ ); 226 people who remained normoglycaemic, were matched for sex, age and BMI with the 230 who became hyperglycaemic (fasting plasma glucose $\geq 6.1 \mathrm{mmol} / \mathrm{l}$ ) at 3 years $[1,18]$.

\section{Fatty Liver Index}

The FLI, a predictor of fatty liver in the general population, is based on an algorithm that includes Body Mass Index (BMI), triglycerides, Gamma-Glutamyl-Transferase (GGT) and waist circumference [19]. In the present study, we dichotomized the FLI into 2 categories, over 70 and under 70, because a FLI value over 70 predicted the onset of type 2 diabetes in our previous study [14].

\section{Genotyping}

Two single nucleotide polymorphisms (SNP) of $C D H 13$ were selected on the basis of previous studies. These SNPs (rs11646213 [A>T] and rs3865188 [A>T]) have been associated with plasma adiponectin levels in GWAS [10,20,21]. They are located in the gene promoter.

All polymorphisms were genotyped in the whole population using Kaspar method by LGC Genomics, Hoddesdon, UK (http://www.lgcgenomics.com). The genotyping success rate was 0.97 for both in D.E.S.I.R. and 0.96 (rs11646213) and 0.97 (rs3865188) in DIABHYCAR.

\section{Statistical Analysis}

The associations between the genotypes and continuous variables were estimated using ANCOVA for repeated measures, with adjustments for confounding factors (age, sex, BMI). Parameters that were not normally distributed (for example the adiponectin levels) were Log transformed before analysis. Associations between baseline adiponectin levels and continuous 
variables were assessed by linear regression, adjusting for confounding variables (sex, age, glycemic status, BMI). Association between baseline adiponectin levels and 9-year prevalence of hyperglycemia was tested by ANCOVA adjusting for sex, age and BMI. Associations between polymorphisms and metabolic diseases used logistic regression, adjusted for confounding factors, and quantified by Odds Ratios (OR) with $95 \%$ confidence intervals (CI). Correction for multiple comparisons due to multiple SNP testing took into account the effective number of independent tests (Meff) based on the degree of linkage disequilibrium between SNPs [22]. A value of $p \leq 0.033$ was considered significant. Departure from the Hardy Weinberg equilibrium was assessed using a $\chi^{2}$ test. P values were 0.04 and 0.17 (rs11646213) and 0.07 and 0.04 (rs3865188) in D.E.S.I.R. and DIABHYCAR, respectively. The tests concerning polymorphisms correspond to the best fitting models of inheritance according to descriptive statistics (additive, dominant or recessive).

Statistical analyses used SYSTAT 13® for Windows.

In the D.E.S.I.R. study, we excluded people born outside mainland France in the genetic analyses. For analyses with the FLI, we only studied the 3650 people with alcohol consumption levels lower than $30 \mathrm{~g} /$ day (men) and $20 \mathrm{~g} /$ day (women).

\section{Results}

\section{D.E.S.I.R. Cohort}

Baseline adiponectin levels were negatively and significantly associated with BMI ( $\mathrm{p}=0.02)$ and FLI $(\mathrm{p}<0.0001)$ and this latter association remained after further adjustment for BMI $(\mathrm{p}=0.0006)$. There was no association with HbA1c $(\mathrm{p}=0.23)$. Plasma adiponectin was also associated with the prevalence of hyperglycaemia at 9 years (ANCOVA adjusted for sex, age and BMI: $\mathrm{p}=0.01$ ). 
The rs11646213 A allele was significantly associated with higher BMI and HbA1c (Table 2) as well as with lower plasma adiponectin levels (Table 3) (adjusted on age, sex and BMI, when appropriate). In people who reported at baseline to drink no alcohol or who had a light alcohol consumption, at the end of the study, the A allele was more frequent in those with FLI $\geq 70$ (OR [95\% CI]: 1.22 [1.00 - 1.49]); but this difference did not reach the statistical threshold of significance $(\mathrm{p}=0.05)$ (Table 4).

The rs3865188 A allele was significantly associated with lower BMI and HbA1c (Table 2), and higher plasma adiponectin levels (Table 3). The association with HbA1c was no longer significant after adjusting for BMI. It was also associated with a lower risk of being in the FLI $\geq 70$ group at baseline (OR [95\% CI]: 0.72 [0.57 - 0.92]; $p=0.01$ ) and at the end of the study (OR [95\% CI]: 0.75 [0.61 - 0.92]; p=0.005) (Table 4).

\section{Association with Type 2 Diabetes}

The genotypes and allele frequencies were similar between the people with type 2 diabetes in D.E.S.I.R. and DIABHYCAR. In order to increase the power of the statistical analysis, we performed a case-control comparison between people without type 2 diabetes in D.E.S.I.R. and the people with type 2 diabetes from DESIR and DIABHYCAR (Table 5). The two polymorphisms were significantly associated with type 2 diabetes, with a higher risk for the minor allele of rs11646213 (OR 1.11, 95\% CI: 1.04-1.19, $\mathrm{p}=0.001)$ and a lower risk for the minor allele of rs3865188 (OR 0.92, 95\% CI: 0.87-0.99, $\mathrm{p}=0.01$ ).

\section{Discussion}

Our main results in the D.E.S.I.R. and DIABHYCAR cohorts show associations of two polymorphisms of $\mathrm{CDH} 13$ with type 2 diabetes, as well as with BMI, FLI and circulating adiponectin levels. 
The two variants were associated with the prevalence of type 2 diabetes in a case-control study including people without type 2 diabetes from D.E.S.I.R. and people with type 2 diabetes from D.E.S.I.R. and DIABHYCAR cohorts. Consistent with this association, in D.E.S.I.R., the type 2 diabetes at-risk alleles were also associated with higher HbA1c levels. To our knowledge, this is the first reporting of an association between $\mathrm{CDH} 13$ variants and the risk of type 2 diabetes in a European Caucasian population. However, in Swedes, rs11646213 was associated with the metabolic syndrome [11] and in East Asian populations, rs3865188 was associated with metabolic parameters, in the same directions as in our study $[13,23,24]$. The mechanisms behind these associations are unclear.

For both polymorphisms, the variants at risk for type 2 diabetes in our study were also associated with lower adiponectin levels. This is consistent with the insulin-sensitizing role of adiponectin[25-27]. Circulating adiponectin levels are negatively associated with the development of type 2 diabetes [28]. Nevertheless, some data concerning the role of $t-$ cadherin in adiponectin action are not consistent with this straightforward explanation. Tcadherin acts as a co-receptor for HMW and MMW adiponectin [7]. In the heart, Denzel et al. showed that t-cadherin was essential for adiponectin-mediated activation of the AMP activated protein kinase signaling pathway. In the same study, plasma adiponectin levels increased in TCAD-KO mice. Despite high circulating adiponectin levels, these animals were not protected from ischemia-reperfusion cardiac injuries. This phenomenon can be interpreted as an adiponectin resistance caused by the absence of $\mathrm{t}$-cadherin necessary for tissue uptake of adiponectin. Accordingly, in our study, the $\mathrm{CDH} 13$ alleles associated with high adiponectin levels should also be associated with adiponectin resistance. Since our findings show that higher levels are concomitant with a lower risk of type 2 diabetes, it indicates that this tcadherin induced adiponectin resistance does not affect the susceptibility to type 2 diabetes as it does with stress induced cardiac injuries. Actually, in agreement with the adiponectin 
resistance hypothesis, Gao et al. found that $\mathrm{CDH} 13$ alleles associated with high circulating adiponectin levels associate with a deleterious metabolic profile [24]. These results are discordant with our data. The difference with our study might be explained by the European origin of the population. Differences in the genetic architecture within the $C D H 13$ locus between Europeans and Asians have been described [29]. Another difference comes from the recruitment procedure. In fact, D.E.S.I.R. is a population-based study while the abovementioned studies included many patients with metabolic diseases where adiponectin resistance might be occurring, therefore inhibiting the protective effect of adiponectin. On a molecular basis, Putku et al. stated that the $C D H 13$ promotor region holds several methylated quantitative trait loci (meQTLs) that they found to be associated with cardiovascular traits [30]. The polymorphisms that we studied are localized in the promoter region harboring those meQTLs and are in linkage disequilibrium with four SNPs exhibiting effect on methylation level. The association of the SNPs we studied with certain metabolic traits might therefore depend on the promoter methylation status that varies across populations, with different lifestyles and genetic backgrounds. Further studies will be necessary to determine whether these SNPs are directly functional or whether they are only linked to causal variants which might be meQTLs.

In the present study, one $C D H 13$ alleles associated with a higher relative risk of type 2 diabetes was also associated with high FLI levels, previously found predictive of type 2 diabetes. Therefore, $\mathrm{CDH} 13$ alleles might be associated with type 2 diabetes through the liver profile. In the absence of hepatocarcinoma, there has been no evidence of $\mathrm{t}$-cadherin expression in hepatocytes [31]. Therefore, the association with type 2 diabetes may be secondary to the association with plasma adiponectin levels. Adiponectin has antisteatotic and antiapoptotic effects on hepatocytes [32]. Adiponectin levels are associated with NAFLD $[3,33]$, and with FLI in the present study. It has been proposed that fatty liver may induce 
insulin resistance [34]. Therefore, $C D H 13$ might influence type 2 diabetes risk by an effect on adiponectin levels and also by an effect on fatty liver. Nevertheless, since the effects on fatty liver likely depend on the effect on adiponectin, these mechanisms are likely closely linked. The connection between these effects may be the ceramide pathway. It has been suggested that ceramides which are associated with insulin resistance play a major role in NAFLD progression [35]. Adiponectin diminishes the accumulation of ceramides by activating ceramidase activity of receptors AdipoR1/R2 [36]. It has been suggested that this latter effect was central to most of the adiponectin actions [36].

The $C D H 13$ variants were also associated with BMI. In East Asian populations, a similar result has sometimes been found $[21,24]$. In a recent large meta-analysis of GWAS data on BMI [37], a $C D H 13$ variant (rs8062451) was associated with BMI $\left(\mathrm{p}=7.33 \times 10^{-6}\right)$. The mechanism of such an association is not known. In our study, this association is in line with the inverse relationship between BMI and adiponectin levels. Nevertheless, when adjusting for BMI, the association with adiponectin persists. The associations between $C D H 13$ alleles and $\mathrm{HbA1c}$ and FLI also persisted after adjustments on BMI, which indicates the independence, at least partial, of these associations. T-cadherin might therefore have independent pleiotropic effects. Actually T-cadherin and plasma adiponectin levels might independently affect the development of type 2 diabetes.

Our study has several limitations. We could not adjust our genetic analyses for population stratification. Nevertheless, only people born in mainland France were analyzed, which should limit the ethnic heterogeneity. Due to the low number of adiponectin measures within the population, we could not adjust our results for plasma adiponectin levels. This adjustment would have allowed us to describe the role of adiponectin in the associations between $C D H 13$ and some phenotypes such as HbA1c. We could not show genetic associations with FLI as a continuous variable. Therefore, since our result is described for the first time, this association 
needs to be replicated. Also, concerning the association with type 2 diabetes, the D.E.S.I.R. study alone lacked statistical power, as it included only 294 people with type 2 diabetes. Nevertheless, we showed associations in this cohort of the two $C D H 13$ polymorphisms with HbA1c and the FLI threshold predictive of type 2 diabetes incidence, consistent with the case control comparison between D.E.S.I.R. and DIABHYCAR.

In conclusion, the two common polymorphisms of $\mathrm{CDH} 13$ are associated with type 2 diabetes, FLI, BMI and circulating adiponectin. Further studies are needed to clarify the mechanisms of these associations in order to determine whether these results indicate new pathways in the pathophysiology of type 2 diabetes and a possible new therapeutic target.

\section{Acknowledgements}

The D.E.S.I.R. Study Group. INSERM U1018: B. Balkau, P. Ducimetière, E. Eschwège; INSERM U367: F. Alhenc-Gelas; CHU D’Angers: A. Girault; Bichat Hospital: F. Fumeron, M. Marre, R Roussel; CHU de Rennes: F. Bonnet; CNRS UMR8090, Lille: S. Cauchi, P. Froguel; Centres d'Examens de Santé: Alençon, Angers, Blois, Caen, Chateauroux, Chartres, Cholet, Le Mans, Orléans, Tours; Institute de Recherche Médecine Générale: J. Cogneau; General practitioners of the region; Institute inter-Regional pour la Santé: C. Born, E. Caces, M. Cailleau, O Lantieri, J.G. Moreau, F. Rakotozafy, J. Tichet, S. Vol.

\section{Funding}

The D.E.S.I.R. study has been supported by INSERM contracts with CNAMTS, Lilly, Novartis Pharma and Sanofi-Aventis; by INSERM (Réseaux en Santé Publique, Interactions entre les déterminants de la santé), Cohortes Santé TGIR, the Association Diabète Risque Vasculaire, the Fédération Française de Cardiologie, La Fondation de France, ALFEDIAM, 
Société francophone du diabète, ONIVINS, Abbott, Ardix Medical, Bayer Diagnostics,

Becton Dickinson, Cardionics, Merck Santé, Novo Nordisk, Pierre Fabre, Roche, Topcon.

The analysis and interpretation of the data has been done without the participation of these organizations and companies.

\section{Conflicts of interest: none}

All authors approved the final version of the manuscript. 


\section{References}

[1] Fumeron F, Aubert R, Siddiq A, Betoulle D, Péan F, Hadjadj S, et al. Adiponectin gene polymorphisms and adiponectin levels are independently associated with the development of hyperglycemia during a 3-year period the epidemiologic data on the insulin resistance syndrome prospective study. Diabetes 2004;53:1150-7.

[2] Jaziri R, Aubert R, Roussel R, Emery N, Maimaitiming S, Bellili N, et al. Association of ADIPOQ genetic variants and plasma adiponectin isoforms with the risk of incident renal events in type 2 diabetes. Nephrol Dial Transplant 2010;25:2231-7. doi:10.1093/ndt/gfp771.

[3] Polyzos SA, Toulis KA, Goulis DG, Zavos C, Kountouras J. Serum total adiponectin in nonalcoholic fatty liver disease: a systematic review and meta-analysis. Metabolism 2011;60:313-26. doi:10.1016/j.metabol.2010.09.003.

[4] Polyzos SA, Kountouras J, Zavos C, Tsiaousi E. The role of adiponectin in the pathogenesis and treatment of non-alcoholic fatty liver disease. Diabetes Obes Metab 2010;12:365-83. doi:10.1111/j.1463-1326.2009.01176.x.

[5] Hug C, Wang J, Ahmad NS, Bogan JS, Tsao T-S, Lodish HF. T-cadherin is a receptor for hexameric and high-molecular-weight forms of Acrp30/adiponectin. Proc Natl Acad Sci U S A 2004;101:10308-13. doi:10.1073/pnas.0403382101.

[6] Philippova M, Joshi MB, Kyriakakis E, Pfaff D, Erne P, Resink TJ. A guide and guard: the many faces of T-cadherin. Cell Signal 2009;21:1035-44.

[7] Denzel MS, Scimia M-C, Zumstein PM, Walsh K, Ruiz-Lozano P, Ranscht B. Tcadherin is critical for adiponectin-mediated cardioprotection in mice. J Clin Invest 2010;120:4342-52. doi:10.1172/JCI43464.

[8] Tyrberg B, Miles P, Azizian KT, Denzel MS, Nieves ML, Monosov EZ, et al. Tcadherin (Cdh13) in association with pancreatic $\beta$-cell granules contributes to second phase insulin secretion. Islets 2011;3:327-37. doi:10.4161/isl.3.6.17705.

[9] Dastani Z, Hivert M-F, Timpson N, Perry JRB, Yuan X, Scott RA, et al. Novel loci for adiponectin levels and their influence on type 2 diabetes and metabolic traits: a multiethnic meta-analysis of 45,891 individuals. PLoS Genet 2012;8:e1002607. doi:10.1371/journal.pgen.1002607.

[10] Jee SH, Sull JW, Lee J-E, Shin C, Park J, Kimm H, et al. Adiponectin Concentrations: A Genome-wide Association Study. Am J Hum Genet 2010;87:545-52. doi:10.1016/j.ajhg.2010.09.004.

[11] Fava C, Danese E, Montagnana M, Sjögren M, Almgren P, Guidi GC, et al. A variant upstream of the CDH13 adiponectin receptor gene and metabolic syndrome in Swedes. Am J Cardiol 2011;108:1432-7. doi:10.1016/j.amjcard.2011.06.068.

[12] Org E, Eyheramendy S, Juhanson P, Gieger C, Lichtner P, Klopp N, et al. Genome-wide scan identifies $\mathrm{CDH} 13$ as a novel susceptibility locus contributing to blood pressure determination in two European populations. Hum Mol Genet 2009;18:2288-96. doi: $10.1093 / \mathrm{hmg} / \mathrm{ddp} 135$.

[13] Chung C-M, Lin T-H, Chen J-W, Leu H-B, Yang H-C, Ho H-Y, et al. A genome-wide association study reveals a quantitative trait locus of adiponectin on $\mathrm{CDH} 13$ that predicts cardiometabolic outcomes. Diabetes 2011;60:2417-23. doi:10.2337/db10-1321.

[14] Balkau B, Lange C, Vol S, Fumeron F, Bonnet F, Group Study D.E.S.I.R. Nine-year incident diabetes is predicted by fatty liver indices: the French D.E.S.I.R. study. BMC Gastroenterol 2010;10:56. doi:10.1186/1471-230X-10-56.

[15] Fumeron F, Lamri A, Abi Khalil C, Jaziri R, Porchay-Baldérelli I, Lantieri O, et al. Dairy consumption and the incidence of hyperglycemia and the metabolic syndrome: results from a french prospective study, Data from the Epidemiological Study on the 
Insulin Resistance Syndrome (DESIR). Diabetes Care 2011;34:813-7. doi:10.2337/dc10-1772.

[16] Marre M, Lievre M, Chatellier G, Mann JFE, Passa P, Ménard J, et al. Effects of low dose ramipril on cardiovascular and renal outcomes in patients with type 2 diabetes and raised excretion of urinary albumin: randomised, double blind, placebo controlled trial (the DIABHYCAR study). BMJ 2004;328:495. doi:10.1136/bmj.37970.629537.0D.

[17] Lièvre M, Marre M, Chatellier G, Plouin P, Réglier J, Richardson L, et al. The noninsulin-dependent diabetes, hypertension, microalbuminuria or proteinuria, cardiovascular events, and ramipril (DIABHYCAR) study: design, organization, and patient recruitment. DIABHYCAR Study Group. Control Clin Trials 2000;21:383-96.

[18] Bonnet F, Balkau B, Malécot JM, Picard P, Lange C, Fumeron F, et al. Sex hormonebinding globulin predicts the incidence of hyperglycemia in women: interactions with adiponectin levels. Eur J Endocrinol Eur Fed Endocr Soc 2009;161:81-5. doi:10.1530/EJE-09-0202.

[19] Bedogni G, Bellentani S, Miglioli L, Masutti F, Passalacqua M, Castiglione A, et al. The Fatty Liver Index: a simple and accurate predictor of hepatic steatosis in the general population. BMC Gastroenterol 2006;6:33. doi:10.1186/1471-230X-6-33.

[20] Wu Y, Gao H, Li H, Tabara Y, Nakatochi M, Chiu Y-F, et al. A meta-analysis of genome-wide association studies for adiponectin levels in East Asians identifies a novel locus near WDR11-FGFR2. Hum Mol Genet 2014;23:1108-19. doi:10.1093/hmg/ddt488.

[21] Morisaki H, Yamanaka I, Iwai N, Miyamoto Y, Kokubo Y, Okamura T, et al. CDH13 gene coding T-cadherin influences variations in plasma adiponectin levels in the Japanese population. Hum Mutat 2012;33:402-10. doi:10.1002/humu.21652.

[22] Nyholt DR. A Simple Correction for Multiple Testing for Single-Nucleotide Polymorphisms in Linkage Disequilibrium with Each Other. Am J Hum Genet 2004;74:765-9.

[23] Kitamoto A, Kitamoto T, Nakamura T, Matsuo T, Nakata Y, Hyogo H, et al. CDH13 Polymorphisms are Associated with Adiponectin Levels and Metabolic Syndrome Traits Independently of Visceral Fat Mass. J Atheroscler Thromb 2015. doi:10.5551/jat.31567.

[24] Gao H, Kim Y-M, Chen P, Igase M, Kawamoto R, Kim MK, et al. Genetic variation in CDH13 is associated with lower plasma adiponectin levels but greater adiponectin sensitivity in East Asian populations. Diabetes 2013;62:4277-83. doi:10.2337/db130129.

[25] Yadav A, Kataria MA, Saini V, Yadav A. Role of leptin and adiponectin in insulin resistance. Clin Chim Acta Int J Clin Chem 2013;417:80-4. doi:10.1016/j.cca.2012.12.007.

[26] Tishinsky JM, Robinson LE, Dyck DJ. Insulin-sensitizing properties of adiponectin. Biochimie 2012;94:2131-6. doi:10.1016/j.biochi.2012.01.017.

[27] Shehzad A, Iqbal W, Shehzad O, Lee YS. Adiponectin: regulation of its production and its role in human diseases. Horm Athens Greece 2012;11:8-20.

[28] Lindsay RS, Funahashi T, Hanson RL, Matsuzawa Y, Tanaka S, Tataranni PA, et al. Adiponectin and development of type 2 diabetes in the Pima Indian population. The Lancet 2002;360:57-8. doi:10.1016/S0140-6736(02)09335-2.

[29] Otsuka I, Watanabe Y, Hishimoto A, Boku S, Mouri K, Shiroiwa K, et al. Association analysis of the Cadherin 13 gene with schizophrenia in the Japanese population. Neuropsychiatr Dis Treat 2015;11:1381-93. doi:10.2147/NDT.S84736.

[30] Putku M, Kals M, Inno R, Kasela S, Org E, Kožich V, et al. CDH13 promoter SNPs with pleiotropic effect on cardiometabolic parameters represent methylation QTLs. Hum Genet 2015;134:291-303. doi:10.1007/s00439-014-1521-6. 
[31] Chan DW, Lee JMF, Chan PCY, Ng IOL. Genetic and epigenetic inactivation of Tcadherin in human hepatocellular carcinoma cells. Int J Cancer 2008;123:1043-52. doi:10.1002/ijc.23634.

[32] Jung TW, Lee YJ, Lee MW, Kim SM, Jung TW. Full-length adiponectin protects hepatocytes from palmitate-induced apoptosis via inhibition of c-Jun NH2 terminal kinase. FEBS J 2009;276:2278-84. doi:10.1111/j.1742-4658.2009.06955.x.

[33] Polyzos SA, Kountouras J, Mantzoros CS. Adipokines in nonalcoholic fatty liver disease. Metabolism n.d. doi:10.1016/j.metabol.2015.11.006.

[34] Grønbaek H, Thomsen KL, Rungby J, Schmitz O, Vilstrup H. Role of nonalcoholic fatty liver disease in the development of insulin resistance and diabetes. Expert Rev Gastroenterol Hepatol 2008;2:705-11. doi:10.1586/17474124.2.5.705.

[35] Promrat K, Longato L, Wands JR, de la Monte SM. Weight loss amelioration of nonalcoholic steatohepatitis linked to shifts in hepatic ceramide expression and serum ceramide levels. Hepatol Res Off J Jpn Soc Hepatol 2011;41:754-62. doi:10.1111/j.1872-034X.2011.00815.x.

[36] Holland WL, Miller RA, Wang ZV, Sun K, Barth BM, Bui HH, et al. Receptor-mediated activation of ceramidase activity initiates the pleiotropic actions of adiponectin. Nat Med 2011;17:55-63. doi:10.1038/nm.2277.

[37] Locke AE, Kahali B, Berndt SI, Justice AE, Pers TH, Day FR, et al. Genetic studies of body mass index yield new insights for obesity biology. Nature 2015;518:197-206. doi:10.1038/nature14177. 
Table 1. Characteristics at inclusion in D.E.S.I.R and DIABHYCAR

\begin{tabular}{lcc}
\hline Clinical data & D.E.S.I.R. & DIABHYCAR \\
\hline $\mathrm{N}(\%$ men $)$ & $5212(50 \%)$ & $3123(73 \%)$ \\
Age $($ years $)$ & $47 \pm 10$ & $65 \pm 8$ \\
BMI $\left(\mathrm{kg} / \mathrm{m}^{2}\right)$ & $24.7 \pm 3.8$ & $29.4 \pm 4.6$ \\
Waist circumference $(\mathrm{cm})$ & $83 \pm 12$ & - \\
Glucose (mmol/l) & $5.4 \pm 0.8$ & $9.6 \pm 3.1$ \\
HbA1c $(\%)$ & $5.3 \pm 0.5$ & $7.9 \pm 1.8$ \\
Insulin (pmol/l) & $39.8(27.8-57.3)$ & - \\
Fatty Liver Index $\geq 70(\%)$ & 11.2 & $5.79 \pm 1.07$ \\
Total Cholesterol (mmol/l) & $5.73 \pm 1.02$ & $1.32 \pm 0.36$ \\
HDL-C (mmol/l) & $1.62 \pm 0.42$ & $3.53 \pm 0.88$ \\
LDL-C (mmol/l) & $3.36 \pm 1.02$ & $1.83(1.30-2.67)$ \\
Triglycerides (mmol/l) & $0.97(0.68-1.43)$ & $82 \pm 8$ \\
Diastolic blood pressure (mm Hg) & $80 \pm 10$ & $144 \pm 13$ \\
Systolic blood pressure (mm Hg) & $131 \pm 16$ & \\
\hline BMI, body mass ind $;$ & & \\
\hline
\end{tabular}

BMI, body mass index;

Data are $\mathrm{N}$ (percentage), means \pm SDs, medians (quartile 1, quartile 3) 
Table 2. Association between the CDH13 rs11646213, rs3865188 variants and metabolic traits in the D.E.S.I.R. study.

\begin{tabular}{|c|c|c|c|c|c|c|}
\hline \multicolumn{2}{|c|}{ Polymorphism } & \multirow[t]{2}{*}{$\mathrm{N}$} & \multicolumn{2}{|c|}{ BMI $\left(\mathrm{kg} / \mathrm{m}^{2}\right)$} & \multicolumn{2}{|c|}{$\mathrm{HbA1c}(\%)$} \\
\hline & & & T0 & T9 & T0 & T9 \\
\hline \multirow[t]{3}{*}{ rs11646213 } & $\mathrm{TT}$ & 1615 & $24.6 \pm 0.1$ & $25.5 \pm 0.12$ & $5.43 \pm 0.01$ & $5.58 \pm 0.02$ \\
\hline & $\mathrm{TA}$ & 2170 & $24.7 \pm 0.08$ & $25.8 \pm 0.1$ & $5.47 \pm 0.01$ & $5.62 \pm 0.01$ \\
\hline & $\mathrm{AA}$ & 827 & $24.9 \pm 0.13$ & $26.0 \pm 0.16$ & $5.48 \pm 0.02$ & $5.64 \pm 0.02$ \\
\hline \multicolumn{3}{|l|}{ p-value * } & \multicolumn{2}{|c|}{0.03} & \multicolumn{2}{|c|}{$0.006 / 0.02$} \\
\hline \multirow[t]{3}{*}{ rs3865188 } & $\mathrm{TT}$ & 1383 & $24.8 \pm 0.1$ & $25.9 \pm 0.12$ & $5.47 \pm 0.01$ & $5.62 \pm 0.02$ \\
\hline & $\mathrm{TA}$ & 2220 & $24.7 \pm 0.08$ & $25.8 \pm 0.1$ & $5.47 \pm 0.01$ & $5.62 \pm 0.01$ \\
\hline & $\mathrm{AA}$ & 993 & $24.5 \pm 0.12$ & $25.4 \pm 0.15$ & $5.43 \pm 0.02$ & $5.58 \pm 0.02$ \\
\hline $\mathrm{p}$-value $*$ & & & \multicolumn{2}{|c|}{0.03} & \multicolumn{2}{|c|}{$0.02 / 0.09$} \\
\hline
\end{tabular}

Data shown are mean \pm SD at inclusion (T0) and at 9-year follow-up (T9)

*p-value of genotype effect by ANCOVA for repeated measures adjusted for sex, age (/ + BMI), when appropriate. Additive model was used except for rs3865188 in HbA1c (recessive model analysis). No significant interactions genotype $\mathrm{x}$ time were found. 
Table 3. Plasma adiponectin levels according to

CDH13 genotypes in a subsample of the D.E.S.I.R.

cohort.

\begin{tabular}{llll}
\hline Polymorphism & & $\mathrm{N}$ & $\begin{array}{l}\text { Adiponectin } \\
(\mu \mathrm{g} / \mathrm{mL})\end{array}$ \\
\hline rs11646213 & TT & 160 & $23.6(15.2-35.9)$ \\
& TA & 191 & $24.0(14.9-38.9)$ \\
& AA & 67 & $21.1(12.8-34.8)$ \\
p-value $^{*}$ & & & $0.03 / 0.008$ \\
\hline rs3865188 & TT & 132 & $22.2(13.5-36.6)$ \\
& TA & 185 & $23.8(15.0-37.7)$ \\
& AA & 99 & $24.5(16.3-37.0)$ \\
p-value $^{*}$ & & & $0.002 / 0.001$
\end{tabular}

Data show are medians (quartile 1, quartile 3) at T0. p-value of genotype effect (additive model groups), adjusted for age, sex, BMI and glycemic status / idem + ADIPOQ polymorphisms 
Table 4. Association between the CDH13 rs11646213 and rs3865188 variants and FLI. The D.E.S.I.R. Study

\begin{tabular}{|c|c|c|c|c|c|c|c|c|c|c|}
\hline & & \multicolumn{4}{|c|}{ At baseline, T0 } & \multicolumn{5}{|c|}{ At 9 year follow-up, T9 } \\
\hline & & \multirow[b]{2}{*}{$\mathrm{N}$} & \multicolumn{2}{|c|}{ FLI $(\%)$} & \multirow[t]{2}{*}{ p-value } & \multirow[t]{2}{*}{ OR $(95 \%$ IC)* } & \multicolumn{2}{|c|}{ FLI (\%) } & \multicolumn{2}{|c|}{ p-value* OR $(95 \%$ IC)* } \\
\hline & & & $<70$ & $\geq 70$ & & & $<70$ & $\geq 70$ & & \\
\hline \multirow[t]{4}{*}{ rs11646213 } & $\mathrm{TT}$ & 1225 & 35.4 & 32.2 & & & 35.8 & 29.8 & & \\
\hline & TA & 1625 & 46.6 & 47.0 & 0.35 & $1.12(0.88-1.43)$ & 46.4 & 47.9 & 0.05 & $1.22(1.00-1.49)$ \\
\hline & AA & 635 & 18.0 & 20.8 & & & 17.8 & 22.3 & & \\
\hline & MAF & & 41.3 & 44.3 & & & 41.0 & 46.3 & & \\
\hline \multirow[t]{4}{*}{ rs3865188 } & $\mathrm{TT}$ & 1074 & 30.3 & 37.6 & & & 30.3 & 37.1 & & \\
\hline & TA & 1649 & 47.5 & 45.9 & 0.010 & $0.72(0.57-0.92)$ & 47.5 & 48.4 & 0.005 & $0.75(0.61-0.92)$ \\
\hline & AA & 759 & 22.2 & 16.5 & & & 22.2 & 14.5 & & \\
\hline & MAF & & 46.0 & 39.5 & & & 46.0 & 38.7 & & \\
\hline
\end{tabular}

Data shown are percentages within FLI classes $<70$ and $\geq 70$;

* p-value and odds-ratios for the minor allele by logistic regression with recessive model for rs11646213 (AA vs. Tx) and dominant model for rs3865188 (TT vs. Ax), adjusted for sex, age, BMI and alcohol consumption.

MAF: minor allele frequency 
Table 5. Genotype and allele frequencies of $\mathrm{CDH} 13$ polymorphisms according to type 2 diabetic status in the DIABHYCAR and D.E.S.I.R. studies

\begin{tabular}{lcccc}
\hline Polymorphism & $\begin{array}{c}\text { Cases from } \\
\text { DIABHYCAR+DESIR }\end{array}$ & $\begin{array}{c}\text { Controls from } \\
\text { D.E.S.I.R. }\end{array}$ & p-value* & OR (95\% IC)* \\
\hline rs11646213 & $1055(32.0)$ & $1521(35.2)$ & 0.001 & $1.11(1.04-1.18)$ \\
TT & $1581(48.0)$ & $2026(46.9)$ & & \\
TA & $656(19.9)$ & $769(17.8)$ & \\
AA & $1075(32.2)$ & $1294(30.1)$ & 0.01 & \\
\hline rs3865188 & $1593(47.8)$ & $2066(48.0)$ & & \\
TT & $666(20.0)$ & $941(21.9)$ & & \\
TA & & & \\
AA &
\end{tabular}

Data shown are $\mathrm{N}(\%)$

* $p$-value and odds-ratios for the minor allele by logistic regression (additive models) 